\title{
Barriers to Intrauterine Device Use at an University-Based Women’s Clinic
}

\author{
Denise Ragland', Nalin Paykachat ${ }^{2}$, Nafisa Dajani ${ }^{3}$ \\ ${ }^{1}$ Department of Pharmacy Practice, University of Arkansas for Medical Sciences, Little Rock, USA \\ ${ }^{2}$ Department of Pharmacy Practice, Division of Pharmaceutical Evaluation and Policy, University of \\ Arkansas for Medical Sciences, Little Rock, USA \\ ${ }^{3}$ Department of Obstetrics and Gynecology, Division of Maternal-Fetal Medicine, University of Arkansas for \\ Medical Sciences, Little Rock, USA \\ Email: dragland@uams.edu
}

Received 16 September 2014; revised 15 October 2014; accepted 8 November 2014

Copyright (C) 2014 by authors and Scientific Research Publishing Inc.

This work is licensed under the Creative Commons Attribution International License (CC BY).

http://creativecommons.org/licenses/by/4.0/

(c) (i) Open Access

\section{Abstract}

Objective: The purpose of this study was to determine the barriers to intrauterine device (IUD) use at a University-Based Women's Clinic. Methods: This study is a cross-sectional survey of a convenience sample of subjects receiving obstetrical care at a University-Based Women's Clinic. Eligible women who consented to participate self-administered a 16-question survey during a routine prenatal visit. Descriptive statistics were used to report participants' demographics and history of contraception use. Additionally, subjects were asked if they would consider IUD use in the future. Results: A total of 160 women participated in this study. The average age of this sample was 24.9 $(S D=6.3)$. The majority were in low income and low education categories. Only $5 \%$ of women reported previous IUD use. $27 \%$ of women surveyed desired more information regarding IUD contraception. 19\% of participants would consider using an IUD in the future and $25 \%$ would consider IUD in the future if they knew more about them. Insurance and financial constraints were cited as barriers to IUD use. $4 \%$ of the sample reported that they had used an IUD previously and were unhappy with it due to pain and discomfort. $18 \%$ would not consider an IUD because they had heard about side effects. $68 \%$ of the surveyed sample reported unintended pregnancies. Conclusion: The two most common barriers to IUD use in this patient population was lack of knowledge and concern about side effects. Increasing patients' knowledge of IUDs has the potential to increase IUD utilization in this clinic population which reported a $68 \%$ rate of unintended pregnancy.

\section{Keywords}

Intrauterine Device, Intrauterine Contraception, IUD Utilization, Barriers, Unintended Pregnancies, Component, Formatting, Style, Styling 


\section{Introduction}

Intrauterine devices (IUDs) are safe, highly effective, long-lasting methods of contraception with a global cumulative pregnancy rate $<2 \%$ at 5 years [1]. Unlike oral contraceptives, which require consistent daily administration for maximum effectiveness, an IUD requires minimal user effort after insertion. Although the initial cost of an IUD is high, payors consider this method the most cost-effective reversible contraception [2] [3]. Noncontraceptive benefits of IUDs are additional advantages. The levonorgestrel IUD significantly reduces menstrual bleeding in women with idiopathic menorrhagia [4]. The non-hormonal TCu380A (copper) IUD is approved for use as an emergency contraceptive if inserted within 5 days of unprotected intercourse [5] and can be left in place for an additional 10 years of ongoing contraception. Based on recommendations of the World Health Organization, an IUD is appropriate for use in most women who desire family planning including nulliparous women and adolescents [6] [7]. The IUD is the most popular reversible contraceptive method worldwide, used by $14 \%$ of women trying to avoid pregnancy [8] [9]. In contrast, only $7.7 \%$ of American women choose this method compared to $17 \%$ in European countries and 27\% in Asian countries [8] [9].

The American College of Obstetricians and Gynecologists (ACOG) endorses increasing the use of long-acting reversible methods of contraception, including IUDs, to reduce unintended pregnancy rates [10]. The United States has established family planning goals in Healthy People 2020 aimed at improving pregnancy planning, spacing, and preventing unintended pregnancy. An objective of these goals is to increase the rate of intended pregnancies to 56\% [11]. Family planning efforts that can help reduce unintended pregnancy include increasing access to contraception, particularly to the more effective and longer acting reversible forms of contraception including IUDs [12].

Despite the availability of IUDs, unintended pregnancy continues to be a major public healthcare issue in the Unites States [12]. The percent of unintended pregnancies in this country has increased from $48 \%$ in 2001 to $51 \%$ in 2008 [13]. An unintended pregnancy is defined as a pregnancy that is mistimed, unplanned, or unwanted at the time of conception. One possible outcome of unintended pregnancies is induced abortion [14]. Many studies have shown that unintended pregnancies are associated with increased risk of physical, emotional, and socioeconomic adversity for the mother and her family [15]. Women with unintended pregnancies are at greater risk of adverse behaviors (e.g., smoking, drinking, inadequate participation in prenatal care) and domestic violence. Children born as a result of a mistimed or unwanted pregnancy can suffer from cognitive deficits, abuse or neglect. Unplanned pregnancies can disrupt the parent's professional and educational goals and strain the family's current and future finances. Last but not least, medical expenditures for unintended pregnancies are estimated to cost U.S. taxpayers roughly $\$ 11$ billion each year, according to 2006 data [16].

Previous studies demonstrate numerous recognized barriers to IUD use, including lack of clinician knowledge or skill [17] [18] low patient awareness of the method [19] and high upfront-costs [10] [20]. Women requesting an IUD for contraception are significantly more likely to have an IUD placed when out-of-pocket expense is less than $\$ 50$ [21]. The Contraceptive CHOICE Project is a prospective cohort study of 10,000 women 14 - 45 years who want to avoid pregnancy for at least 1 year and are initiating a new form of reversible contraception. An early analysis of the first 2500 women enrolled in this study reported that $56 \%$ of the women chose IUDs if the financial barrier of IUD cost was removed [22]. A subsequent study examined differences in contraception choices among Family PACT clients in California [23]. This project reported that the methods women received differed substantially by race and ethnicity in this low-income population despite the elimination of financial barriers to method choice.

In 2008, 57\% of pregnancies in Arkansas were unintended [24], a rate higher than the national average of $51 \%$. Also in 2008, 73\% of births in Arkansas resulting from unintended pregnancies were publicly funded. Any decrease in the number of mistimed, unplanned, or unwanted pregnancies has the potential to decrease state healthcare spending. Causes of unintended pregnancy are numerous and may include lack of contraception use, incorrect contraception use, barriers to contraception access and misinformation regarding contraceptive methods. This study was designed to investigate various barriers to IUD use at a University-based Women's Clinic located in Arkansas.

\section{Methods}

This study is a cross-sectional self-administered survey using a convenience sample of 18 - 45-year-old patients receiving routine prenatal care at the University Women's Clinic between June and November 2011. Participa- 
tion was strictly voluntary. English-speaking subjects who verbally consented to participate were recruited while waiting to see their health care provider. The selection of the participants was determined by the availability of the research assistant administering the surveys. The self-administered 16-question paper-and-pencil survey included demographics, pregnancy intention, information regarding previous birth control methods and emergency contraception utilization, intention to use an IUD in the future, and an optional request to learn about various birth control methods. After the survey, each participant had the opportunity to discuss the survey items and ask questions related to birth control methods of interest. The entire survey process took approximately 10 - 15 minutes to complete. No incentive was provided. The study was approved by the appropriate institutional review board. Descriptive statistics were utilized in this study. We reported participants' demographics, history of contraception use, and information related to self-reported IUD use.

\section{Results}

A total of 160 women participated in this study. The average age of this sample was 24.9 years (SD $=6.3$ ), Table 1. Ninety-six percent of the participants were Caucasian and African-American. The majority was single (not married) with annual household income of $\leq \$ 20,000$ (84\%). Fifty-four percent reported their education level at high school or less. Sixty-eight percent of the participants reported that their current pregnancy was unintended.

The most commonly used birth control methods reported were condoms (62\%), oral contraceptive pills (61\%), depot medroxyprogesterone acetate (DMPA) injections (38\%), and coitus interruptus/withdrawal (36\%), Table 2. Only $5 \%$ of this sample reported using an IUD previously. Nineteen percent specified that they would consider using an IUD in the future. An additional 25\% would consider IUD in the future if they knew more about them (Figure 1). When asked, "Which birth control method would you like to know more about?" (Table 3), the IUD was the most common answer (27\%). Age did not play a role in subjects' desire for more information about IUD. The average age of participants requesting more information concerning IUDs was 23.4 (SD = 5.07), compared to 25.5 (SD = 6.6) for participants not requesting information.

Only $4 \%$ of IUD users reported that they were unhappy with this method due to pain, discomfort, and/or bleeding (Figure 1). Eighteen percent would not consider an IUD because they had heard about side effects. Lack of insurance or payment problems were potential barriers to IUD use in $9 \%$ of participants. Twenty-six percent reported they would not consider IUD use in the future for a variety of reasons including religious beliefs, indecision regarding future pregnancies, or the desire for permanent, irreversible contraception.

\section{Discussion}

Lack of knowledge is a major barrier to IUD use considering that $25 \%$ of subjects in this study reported that they would consider using this method if they knew more about it. Combining this fraction of subjects with the additional $19 \%$ that stated they would consider an IUD in the future results in $44 \%$ potential users. Given that $68 \%$

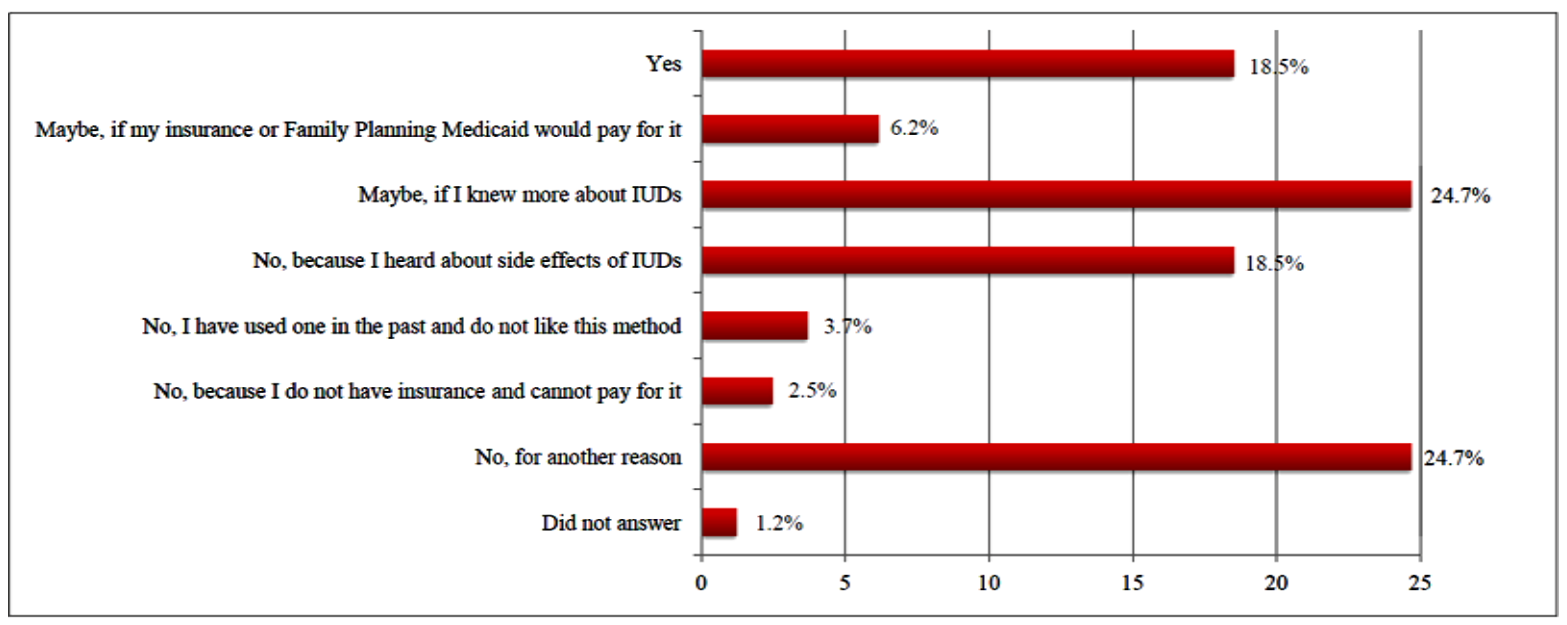

Figure 1. Self-reported interest in using an IUD in the future. 
Table 1. Participant demographics $\left(n=160^{\mathrm{a}}\right)$.

\begin{tabular}{ccc}
\hline & $\mathrm{N}^{\mathrm{a}}$ & $\mathrm{N}(\%)$ \\
\hline Age, years (Mean \pm SD) & & $24.9 \pm 6.3$ \\
$<18$ years & 160 & $19(11 \%)$ \\
$18-29$ years & & $35(21 \%)$ \\
$30-39$ years & & $12(7 \%)$ \\
$\geq 40$ years & & $75(47 \%)$ \\
Race & 159 & $78(49 \%)$ \\
African-American & & $6(4 \%)$ \\
Caucasian & & $103(66 \%)$ \\
Hispanic & & $40(26 \%)$ \\
Marital status & 157 & $13(8 \%)$ \\
Single & & $1(1 \%)$ \\
Married & & $85(54 \%)$ \\
Divorced & & $74(46 \%)$ \\
Widowed & 159 & $109(84 \%)$ \\
Education & & $21(16 \%)$ \\
High school or less & & \\
Some college or above & 130 & \\
Income & & \\
$\leq \$ 20,000$ & & \\
$>\$ 20,000$ & &
\end{tabular}

${ }^{\mathrm{a}}$ Numbers $<160$ are due to missing data.

Table 2. Self-reported previous birth control method utilization.

\begin{tabular}{|c|c|c|}
\hline Method & $\mathrm{N}$ & $(\%)$ \\
\hline Condom & 104 & $(61.5)$ \\
\hline Pill & 103 & $(61.0)$ \\
\hline Medroxyprogesterone Acetate Injection & 64 & $(37.9)$ \\
\hline Withdrawal & 60 & $(35.5)$ \\
\hline Patch & 17 & $(10.1)$ \\
\hline Vaginal Ring & 16 & $(9.5)$ \\
\hline Emergency Contraceptive Pills & 11 & $(6.5)$ \\
\hline IUD & 9 & $(5.3)$ \\
\hline Female Condom & 4 & $(2.4)$ \\
\hline Jelly & 4 & $(2.4)$ \\
\hline Rhythm Method & 3 & $(1.8)$ \\
\hline Diaphragm & 3 & (1.8) \\
\hline Foam & 3 & $(1.8)$ \\
\hline Hormonal Implant & 2 & $(1.2)$ \\
\hline Suppository & 2 & $(1.2)$ \\
\hline Vasectomy & 2 & $(1.2)$ \\
\hline Tubal Ligation & 2 & $(1.2)$ \\
\hline Sponge & 1 & $(0.6)$ \\
\hline Cervical Cap & 0 & 0 \\
\hline
\end{tabular}


Table 3. Self-reported interest in learning about birth control methods.

\begin{tabular}{|c|c|c|}
\hline Method & $\mathrm{N}$ & (\%) \\
\hline IUD & 45 & $(26.6)$ \\
\hline Pill & 31 & (18.3) \\
\hline Tubal Ligation & 24 & $(14.2)$ \\
\hline Vaginal Ring & 15 & $(8.9)$ \\
\hline Hormonal Implant & 12 & $(7.1)$ \\
\hline Patch & 12 & $(7.1)$ \\
\hline Female Condom & 7 & $(4.1)$ \\
\hline Emergency Contraceptive Pills & 6 & (3.6) \\
\hline Cervical Cap & 6 & (3.6) \\
\hline Jelly & 5 & (3.0) \\
\hline Sponge & 4 & $(2.4)$ \\
\hline Condom & 3 & (1.8) \\
\hline Withdrawal & 3 & (1.8) \\
\hline Vasectomy & 3 & (1.8) \\
\hline Medroxyprogesterone Acetate Injection & 1 & $(0.6)$ \\
\hline Diaphragm & 1 & $(0.6)$ \\
\hline Foam & 1 & $(0.6)$ \\
\hline Suppository & 1 & $(0.6)$ \\
\hline Rhythm Method & 1 & $(0.6)$ \\
\hline
\end{tabular}

reported a current unintended pregnancy, IUD utilization, and use of other long-acting reversible contraceptives, should be encouraged in this patient population.

Misinformation is another potential barrier considering that some women citied "history of blood clots" and "birth control causes strokes and seizures" as reasons they would not use an IUD. This may mean that clinicians are not educating patients on this effective form of contraception. Furthermore, healthcare providers may be doing an inadequate job providing information regarding financial resources available for this contraceptive method. Nine percent of subjects listed finances as a barrier $(6.17 \%+2.47 \%$, Table 3$)$ yet most insurance providers will pay for all or some of IUD placement costs. In addition, family planning services provided through Arkansas Health Departments, for women who are under- or uninsured, provide IUDs at little to no patient-cost through funded grants.

Nineteen percent reported they would not consider using IUDs because they heard about side effects. It is possible that these decisions were based on inaccurate or outdated information. The Dalkon Shield used from 1971 to 1974 became infamous for its associated increased risk of ascending bacterial infections leading to sepsis, injury, miscarriage, and death [25] yet this IUD is no longer available. Lack of knowledge or misinformation about IUDs is not uncommon [19] [26]. Yet IUD counseling can prove very effective. More than $50 \%$ of young women surveyed thought positively about IUDs after being educated about them [27] [28].

Healthcare providers' lack of knowledge and IUD misconceptions may be an additional factor in the underutilization of IUDs in North America. A substantial proportion of surveyed family medicine practitioners believed that the side effects of IUDs were more severe than is supported by clinical guidelines and were misinformed about the range of women who could benefit from IUDs [18]. The lack of consistent and accurate knowledge about contraception among providers has the potential to dramatically affect providers' ability to provide quality contraceptive care for their patients, which could have an impact on their ability to prevent unintended pregnan- 
cies [29]. In a 2008 poll of 816 health care providers, which included 399 physicians and 402 advanced practice clinicians, $40 \%$ did not offer intrauterine contraception to any patients who sought contraception [30].

\section{Limitations and Future Studies}

This pilot study yielded preliminary data for future investigations of barriers to IUD use in this population. Like others of its kind, this study has some limitations. The study used a cross-sectional convenience sample rather than a random sampling technique. Additionally, the sample included only English-speaking patients receiving care at one clinic site, which provides care for low-income women throughout the state of Arkansas. Due to these limitations, the findings of this descriptive study may not be generalized to other patient populations or other geographic settings. The findings from this study should be confirmed with additional, longitudinal studies including subjects from various socioeconomic classes with varying degrees of education. Further inquiry about the women's perception of adverse IUD effects would assess if their knowledge is based on accurate information. This might help identify common misconceptions that providers might target in counseling about IUD use. Additionally, this study did not look at barriers from a healthcare provider standpoint. A survey designed to assess the providers' knowledge of IUD availability, contraindications, and efficacy rates at this clinic may uncover additional knowledge deficits that could potentially be addressed with educational programs.

\section{Conclusion}

The two most common barriers to IUD use in this patient population was lack of knowledge and concern about IUD side effects. By educating patients and increasing their awareness of efficacy, availability, and advantages of IUDs, use of this method may become more prevalent. Increasing the utilization of this extremely effective contraceptive can potentially decrease the current unintended pregnancy rate of $68 \%$ in this clinic population.

\section{References}

[1] Thonneau, P.F. and Thierry, E.A. (2008) Contraceptive Efficacy of Intrauterine Devices. American Journal of Obstetrics and Gynecology, 19, 248-253. http://dx.doi.org/10.1016/j.ajog.2007.10.787

[2] Trussell, J., Lallac, A.H., Doan, Q.V., Reyes, E., Pinto, L. and Gricar, J. (2009) Cost Effectiveness of Contraceptives in the United States. Contraception, 79, 5-14. http://dx.doi.org/10.1016/j.contraception.2008.08.003

[3] Trussel, J., Hassan, F. and Lowin, J. (2014) Achieving Cost-Neutrality with Long-Acting Reversible Contraceptive Methods. Contraception. http://www.ncbi.nlm.nih.gov/pubmed/25282161 http://dx.doi.org/10.1016/j.contraception.2014.08.011

[4] American College of Obstetricians and Gynecologists (2006) Noncontraceptive Benefits of the Levonorgestrel Intrauterine System. Obstetrics \& Gynecology, 10, 1479-1482. http://www.ncbi.nlm.nih.gov/pubmed/16738186

[5] Zhou, L. and Xiao, B. (2001) Emergency Contraception with Multiload Cu-375 SL IUD: A Multicenter Clinical Trial. Contraception, 64, 107-112. http://dx.doi.org/10.1016/S0010-7824(01)00231-1

[6] The World Health Organization (2008) Medical Eligibility Criteria for Contraceptive Use, 2008 Update. http://whqlibdoc.who.int/hq/2008/WHO_RHR_08.19_eng.pdf'

[7] American College of Obstetricians and Gynecologists (2011) Long-Acting Reversible Contraception: Implants and Intrauterine Devices. Obstetrics \& Gynecology, 118, 184-196. http://dx.doi.org/10.1097/AOG.0b013e318227f05e

[8] United Nations (2011) World Contraceptive Use. http://un.org/esa/population/publications/contraceptive2011/contraceptive2011.htm

[9] Buhling, K.J., Zite, N.B., Lotke, P. and Black, K. (2014) Worldwide Use of Intrauterine Contraception: A Review. Contraception, 89, 162-173. http://dx.doi.org/10.1016/j.contraception.2013.11.011

[10] American College of Obstetricians and Gynecologists (2009) Increasing Use of Contraceptive Implants and Intrauterine Devices to Reduce Unintended Pregnancy. Obstetrics \& Gynecology, 114, 1434-1438. http://dx.doi.org/10.1097/AOG.0b013e3181c6f965

[11] US Department of Health and Human Services (2012) Healthy People 2020. Family Planning Topic Area. http://www.healthypeople.gov/2020/topicsobjectives2020/overview.aspx?topicid=13

[12] Finer, L.B. and Henshaw, S.K. (2006) Disparities in Rates of Unintended Pregnancy in the United States, 1994 and 2001. Perspectives on Sexual and Reproductive Health, 38, 90-96. http://dx.doi.org/10.1363/3809006

[13] Blumenthal, P.D., Voedisch, A. and Gemzell-Danielsson, K. (2010) Strategies to Prevent Unintended Pregnancy: Increasing Use of Long-Acting Reversible Contraception. Human Reproduction Update, 17, 121-137. 
http://dx.doi.org/10.1093/humupd/dmq026

[14] Guttmacher Institute (2013) Unintended Pregnancy in the United States. http://www.guttmacher.org/pubs/FB-Unintended-Pregnancy-US.html

[15] Brown, S.S. and Eisenberg, L. (1995) The Best Intentions: Unintended Pregnancy and the Well-Being of Children and Families. National Academy Press, Washington DC.

[16] Sonfield, A., Kost, K., Gold, R.B. and Finer, L.B. (2011) The Public Costs of Births Resulting from Unintended Pregnancies: National and State-Level Estimates. Perspectives on Sexual and Reproductive Health, 43, 94-110. http://dx.doi.org/10.1363/4309411

[17] Rubin, S.E., Fletcher, J., Stein, T., Segall-Gutierrez, P. and Gold, M. (2011) Determinants of Intrauterine Contraception Provision among US Family Physicians: A National Survey of Knowledge, Attitudes and Practice. Contraception, 83, 472-478. http://dx.doi.org/10.1016/j.contraception.2010.10.003

[18] Stubbs, E. and Schamp, A. (2008) The Evidence Is In. Why Are IUDs Still Out? Family Physicians' Perceptions of Risk and Indications. Canadian Family Physician, 54, 560-566. http://www.ncbi.nlm.nih.gov/pubmed/18411385

[19] Fleming, K.L., Sokoloff, A. and Raine, T.R. (2010) Attitudes and Beliefs about the Intrauterine Device among Teenagers and Young Women. Contraception, 82, 178-182. http://dx.doi.org/10.1016/j.contraception.2010.02.020

[20] Chiou, C.F., Trussell, J., Reyes, E., Knight, K., Wallace, J., Udani, J., Oda, K. and Borenstein, J. (2003) Economic Analysis of Contraceptives for Women. Contraception, 68, 3-10. http://dx.doi.org/10.1016/S0010-7824(03)00078-7

[21] Gariepy, A.M., Simon, E.J., Patel, D.A., Creinin, M.D. and Schwarz, E.B. (2011) The Impact of Out-of-Pocket Expense on IUD Utilization among Women with Private Insurance. Contraception, 84, e39-e42. http://dx.doi.org/10.1016/j.contraception.2011.07.002

[22] Secura, G.M., Allsworth, J.E., Madden, T., Mullersman, J.L. and Peipert, J.F. (2010) The Contraceptive CHOICE Project: Reducing Barriers to Long-Acting Reversible Contraception. American Journal of Obstetrics \& Gynecology, 203, 115.e1-115.e7. http://www.ncbi.nlm.nih.gov/pubmed/20541171

[23] Dehlendorf, C., Foster, D.G., Bocanegra, H.T., Brindis, C., Bradsberry, M. and Darney, P. (2011) Differences in Contraception among Low-Income Women: Methods Received By Family PACT Clients, California, 2001-2007. Perspectives on Sexual and Reproductive Health, 43, 181-187. http://dx.doi.org/10.1363/4318111

[24] Guttmacher Institute (2014) State Facts about Unintended Pregnancy: Arkansas. http://www.guttmacher.org/statecenter/unintended-pregnancy/pdf/AR.pdf

[25] Centers for Disease Control (1983) Elevated Risk of Pelvic Inflammatory Disease Among Women Using the Dalkon Shield. MMWR, 32, 2221-2222.

[26] Russo, J.A., Miller, E. and Gold, M.A. (2013) Myths and Misconceptions about Long-Acting Reversible Contraception. Journal of Adolescent Health, 52, S14-S21. http://dx.doi.org/10.1016/j.jadohealth.2013.02.003

[27] Stanwood, N.L. and Bradley, K.A. (2006) Young Pregnant Women’s Knowledge of Modern Intrauterine Devices. Obstetrics \& Gynecology, 108, 1417-1422. http://dx.doi.org/10.1097/01.AOG.0000245447.56585.a0

[28] Whitaker, A.K., Johnson, L.M. and Harwood, B. (2008) Adolescent and Young Adult Women's Knowledge of and Attitudes toward the Intrauterine Device. Contraception, 78, 211-217.

http://dx.doi.org/10.1016/j.contraception.2008.04.119

[29] Dehlendorf, C., Levy, K., Ruskin, R. and Steinauer, J. (2010) Health Care Providers’ Knowledge about Contraceptive Evidence: A Barrier to Quality Family Planning Care? Contraception, 81, 292-298. http://dx.doi.org/10.1016/j.contraception.2009.11.006

[30] Harper, C.C., Blum, M., de Bocanegra, H.T., Darney, P.D., Speidel, J.J., Policar, M. and Drey, E.A. (2008) Challenges in Translating Evidence to Practice: The Provision of Intrauterine Contraception. Obstetrics \& Gynecology, 111, 13591369. http://dx.doi.org/10.1097/AOG.0b013e318173fd83 
Scientific Research Publishing (SCIRP) is one of the largest Open Access journal publishers. It is currently publishing more than 200 open access, online, peer-reviewed journals covering a wide range of academic disciplines. SCIRP serves the worldwide academic communities and contributes to the progress and application of science with its publication.

Other selected journals from SCIRP are listed as below. Submit your manuscript to us via either submit@scirp.org or Online Submission Portal.
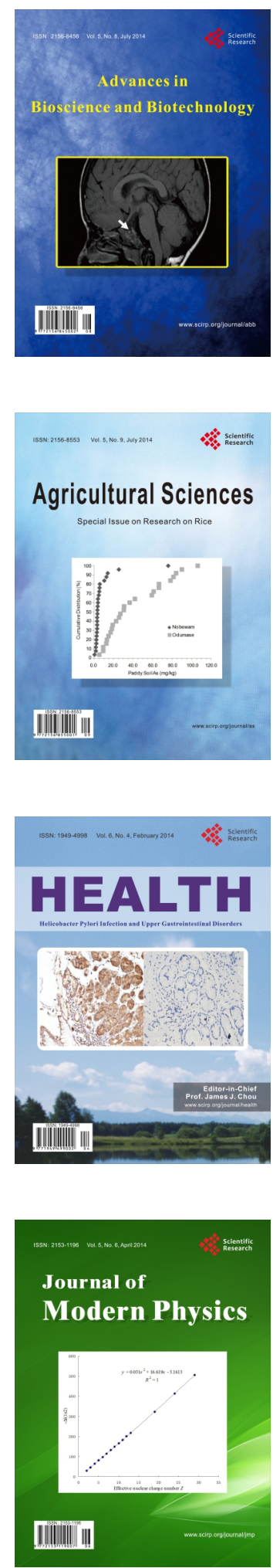
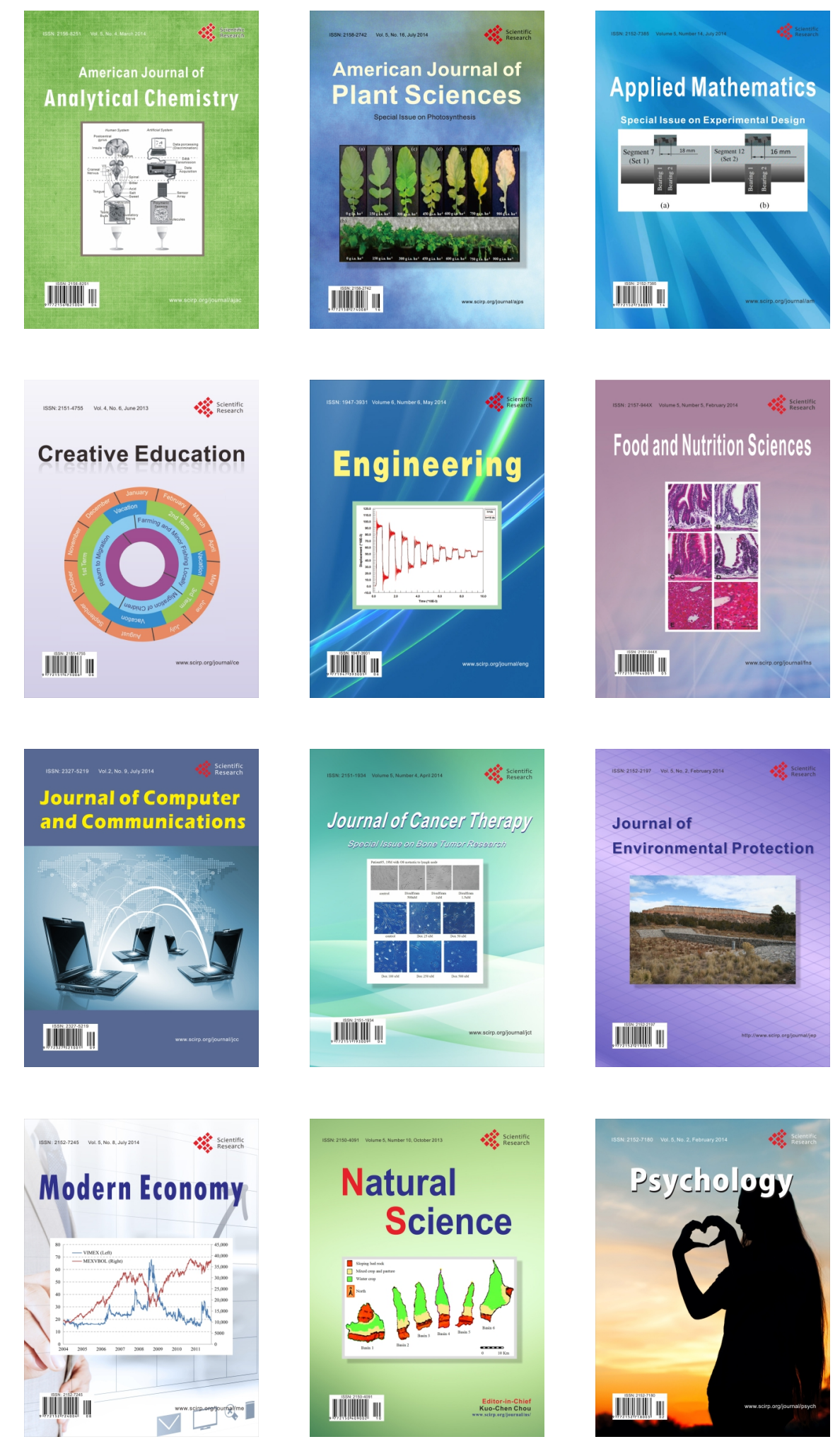